tory suite and they concluded that the virus must therefore have escaped from the smallpox room. The group then discovered that not all smallpox work had been carried out inside the room's safety cabinet and some work with an aspirator to suck off fluid from cell cultures had been undertaken on an open bench.

The principal means of transmission of smallpox viruses is probably by aerosol, in tiny droplets of fluid that form when a pipette is used to deliver drops onto a gel or whenever there is splashing of fluid containing the virus. According to Dr Mark Darlow, head of the safety department at the Porton germ warfare establishment for 25 years, the virus is also very stable; so that once airborne it is a potential killer. An efficient air withdrawal and filtration system over any experiment is therefore essential. But many academics still believe that "what was good enough for Pasteur is good enough for me", said Dr Darlow last week.

According to the Shooter report "the opening and closing of the smallpox room door and the passage in and out by whoever was conducting work on the virus would have created the opportunity for any airborne virus to escape into the animal pox room".
The consequent danger was made all the worse because gowns worn in the smallpox room were not removed on leaving.

Even more seriously, the service ducts in the animal pox room and the smallpox room both had gaps which could allow the leakage of viruses. In particular, the telephone room above, which was connected by the duct to the animal pox room, was used frequently by Mrs Parker, when she was telephoning suppliers to order photographic materials. "A check of the orders placed by Mrs Parker during this period reveals that on 25 July she placed an unusually large number of orders. The relevant strain of smallpox virus, Abid, was being handled in the smallpox room on July 24 and 25 ", the report states.

The committee, although not certain by what route Mrs Parker was infected, concluded that escape via the service duct in the animal pox room was therefore the most probable route of escape of the virus. However, the virus could have reached the corridor outside the laboratory suite and Mrs Parker could have been infected when visiting the inquiry office or the darkroom at the end of the corridor. This was a less likely route, though, and was

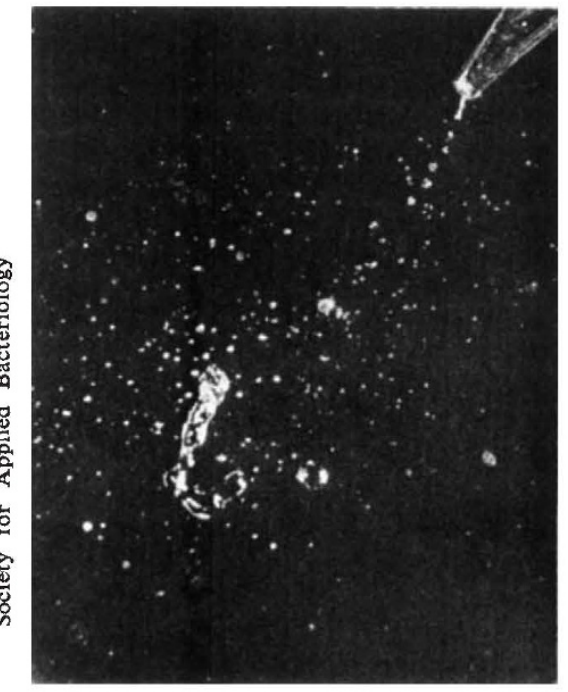

An aerosol resulting from a bubble burst at a pipette tip when the last drop was expelled. This explains how smallpox virus might have escaped into the air.

used by many other persons.

And although they could not be certain about the exact route, the Shooter committee was certain that a combination of poor laboratory procedures, amounting to a major breach in containment policy, was responsible for the outbreak.

\title{
All safety nets failed, says Shooter
}

The report of the Shooter inquiry into the causes of the smallpox outbreak in Birmingham last year finds fault with the three major organisations--the Dangerous Pathogens Advisory Group (DPAG), the World Health Organisation (WHO) and Birmingham University-which were concerned in some way with either running or monitoring the smallpox laboratory at the Department of Medical Microbiology at Birmingham University.

\section{DPAG}

The Dangerous Pathogens Advisory Group (DPAG) exists precisely to prevent the sort of event which occurred at Birmingham. It was created in 1975 in the wake of a previous outbreak of smallpox from a laboratory in London in 1973. Shortly after it came into being it began to formulate a code of practice for work with category A pathogens-those recognised as the most dangerous-and to inspect all laboratories known to hold them.

In February 1976, DPAG's inspector visited the Birmingham laboratory. During the time he was there, says the Shooter report, no work on smallpox was being done. He tested the airflow through the safety cabinet and then spent most of his visit talking to Professor Bedson about smallpox work.
The Shooter report criticises the DPAG inspector for not finding out enough about the "range and extent of the work being done". He did not, says the report, "ask about work with tissue cultures"; neither did he ask about the methods of harvesting virus. "These points seem to us to be of considerable importance", the report goes on, "since one of the unsatisfactory features... was the necessity to pass in and out of the smallpox room during the course of work with smallpox to place cultures in the incubators and to use the low speed centrifuge".

Despite the fact that the Birmingham lab lacked some of the facilities then recommended for use with category A pathogens, namely an air lock, shower, changing facilities and double autoclave, the DPAG inspector recommended to DPAG that the laboratory be approved. He based his judgement on Professor Bedson's reputation as an "experienced and safety-conscious virologist" and the fact that the few named people working on smallpox always did so under Bedson's supervision. There was also a "highly efficient vaccination programme" in force.

When DPAG came to discuss the inspector's report (it meets twice yearly) it felt that it could use its discretionary powers-granted to it when it was created-to recommend approval of the laboratory to the DHSS despite the shortcomings. It added, however, that "fresh clearance should be sought in the event of significant changes in staff, facilities or work programme".

The committee of inquiry felt that the inspector's report did not give DPAG sufficient information on which to base a recommendation. It criticises DPAG for not insisting on an inspection report that compared the facilities and procedures with those laid out in its own safety code and recommends that in future DPAG inspectors should compare laboratories' facilities against a detailed check list. It also criticises the way in which DPAG exercised its discretionary powers and recommends that in future "discretion should be exercised by DPAG only if alternative arrangements are in force in a category A laboratory which are able to achieve a degree of safety equivalent to that specified in the safety code."

Since the inspection in 1976, says the report, changes had taken place in the smallpox laboratory. Professor Bedson had ceased to do experiments because of other commitments and most of the work had been taken over by a PhD student. This had not been explained to the DPAG inspector. In addition 


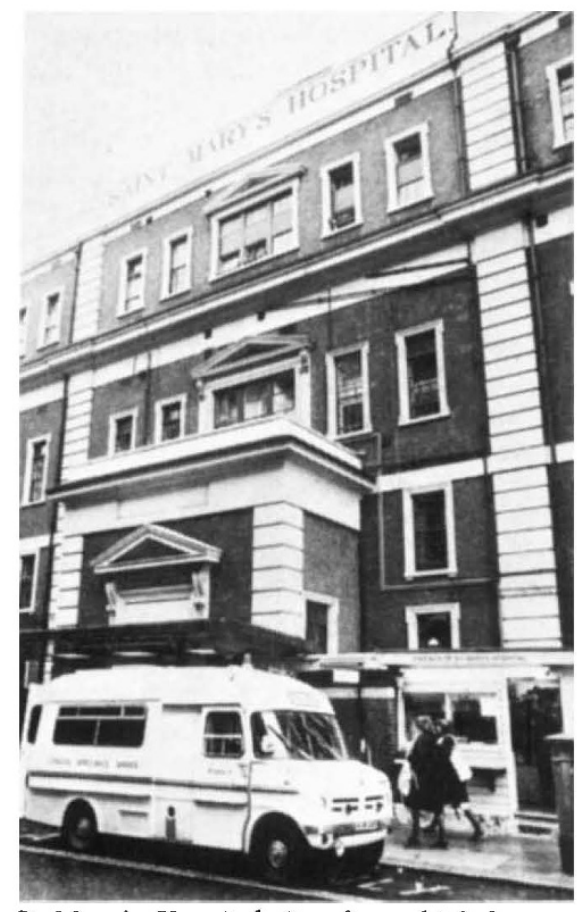

St Mary's Hospital, London which houses the UK's only smallpox laboratory.

the volume of work increased. Twenty two additional strains of variola virus were delivered to the laboratory in early 1978.

DPAG, says the report, was notified of none of these changes. The report therefore recommends that as well as notifying DHSS of any changes, category A laboratories should be reviewed annually. It also suggests that notification of intention to hold category A pathogens should be compulsory and that DPAG should start inspecting all other category A laboratories immediately. Finally, it says, the need to work with variola virus in the UK should be reviewed. If it is decided that work should go on, then, the report recommends, the one remaining laboratory in the UK holding the virus, at St. Mary's Hospital, London, should be moved into the country.

\section{Birmingham University}

Birmingham University and the Department of Medical Microbiology both had safety policies at the time of the smallpox outbreak which should have had some influence on the way research on smallpox was conducted. The committee of inquiry found, however, that there was no "effective system of determining whether both . safety policies were being regularly implemented".

The responsibility of putting the safety codes into practice rested with Professor Bedson as head of department. Responsibility for formulating the safety code specific to microbiological research, however, rested with the committee for the control of pathogenic organisms and infectious materials (CCPOIM), a subcommittee of the university's central safety committee, whose members came solely from the academic staff.

Since the inspection of all departments working with microorganisms by CCPOIM in 1975 there had been no further inspections, says the report. It therefore recommends that "expert safety inspections" should be carried out regularly. It also suggests that a head of department should not be a "member of the team that inspects his own department" (in 1975, Professor Bedson's had been one of the inspecting team), and that the membership of the CCPOIM be extended to include members of the non-academic university staff.

The committee of inquiry also found the experience of the staff working in the smallpox laboratory lacking. Apart from a technician who had worked with smallpox for 11 years and had been trained by Professor Bedson, the other people working on smallpox were a former $\mathrm{PhD}$ student, who joined the laboratory in 1974, and a trainee technician who had been working at the lab for about a year. "As far as we know", says the report, the former PhD student "was never formally trained in the special precautions required for work with smallpox viruses". The trainee technician, who joined the lab straight after leaving school, had apparently started working with smallpox virus "only nine months after she had joined the laboratory".

The report says that this state of affairs was inadequate. It recommends that the university review its policy for instructing staff in laboratory techniques and safety precautions and that it ensures that "the staff are not permitted to carry out such work without appropriate . . . supervision".

\section{WHO}

The WHO had been corresponding with Professor Bedson about safety without the knowledge of either the Birmingham University authorities or the DHSS.

"It is anomalous", says the report, "that though WHO had decided the work could not be supported after the end of 1978 this was not communicated to DHSS or the university". It recommends that in future "institutions should ensure that all dealings with outside bodies concerning work with safety implications in their departments are monitored by the central administration. . . . Its recommendation to the WHO is that it should "maintain a closer liaison with the responsible government authority regarding its dealings with category A pathogen laboratories and in particular with regard to the safety of those laboratories".
WHO had serious doubts on safety in
smallpox lab

WHEN Mrs Parker contracted smallpox, Professor Bedson and his researchers at Birmingham were working under considerable pressure. They wanted to complete their programme of research on smallpox virus by the end of 1978 when their laboratory was due to close.

The 1978 deadline for the completion of the smallpox work had been decided in 1977 when the World Health Organisation (WHO) informed Bedson that his laboratory had not been chosen as a WHO Collaborating Centre for Poxvirus Research. "It was felt", said the WHO in its letter to Bedson on 16 September, 1977 informing him of its decision, "that ... the creation of another official centre would give the impression that WHO is itself increasing the danger of laboratory accidents. ..." In spite of this decision, however, the WHO went on to say that the work at Birmingham was "extremely important and should be supported". It promised Bedson a $\$ 7,500$ grant for 1977 .

In his reply of 4 October, Bedson described the news that his laboratory was not to become a collaborating centre as "a bit of a bombshell". The policy of the UK Department of Health and Social Security (DHSS) was that smallpox research in the UK should only go on in official WHO centres. The implication, therefore, was that Bedson's lab would have to close. This would mean that the work would now have to be done on a shortened timescale, wrote Bedson. "If pressed for a date", he went on, "I would have thought that we should aim to complete our studies with smallpox/whitepox viruses by the end of 1978".

After the WHO's response of 18 October agreeing to Bedson's plan there was a pause in correspondence until late February 1978. From then until 24 August, the day Mrs Parker's illness was diagnosed, all correspondence concerned the visit by WHO inspectors to the Birmingham laboratory on 4 May.

Before the visit took place, Bedson was eager to point out that the Birmingham facilities in no way matched those set out for the WHO's definitive smallpox labs. "It would be expensive and very costly in time", he wrote on 31 March, "if we were to try and establish such a laboratory and 